\title{
Evidence for immunological (allergic) mechanisms in a subgroup of patients with phenprocoumon-induced liver disease
}

\author{
Reinhild Klein
}

Received: 22 May 2009/Accepted: 9 July 2009/Published online: 30 July 2009

(C) Springer-Verlag 2009

\begin{abstract}
Purpose Phenprocoumon-induced liver injury is a rare complication of oral anticoagulation. The mechanisms leading to this side effect are not entirely clear. Here we present data that at least in a subgroup of patients in whom phenprocoumon-induced liver disease was suspected, immunological processes may play an important role.

Patients and methods Thirty patients with suspected phenprocoumon-induced liver disease from different hospitals in Germany were analyzed. Peripheral blood mononuclear cells (PBMC) of these patients were tested in the lymphocyte transformation test (LTT) for reactivity with phenprocoumon in vitro. As controls, PBMC were isolated from ten individuals treated with phenprocoumon but without any side effects, and from ten healthy individuals who have never received the drug.

Results Fifteen of the 30 patients had sensitized lymphocytes toward phenprocoumon as shown by LTT. Four patients had taken the drug for more than 5 years; in one patient, liver disease appeared after 1 day of phenprocoumon intake. There was no correlation between a positive LTT and clinical/ laboratory parameters. None of the 20 controls had sensitized lymphocytes toward phenprocoumon.

Conclusions Applying the LTT, we were able to unravel the cause of suspected phenprocoumon-induced liver injury as a drug allergic reaction in 15 out of 30 analyzed patients.
\end{abstract}

Keywords Allergy · Drug-induced liver injury .

Lymphocyte transformation test $\cdot$ Phenprocoumon

R. Klein $(\bowtie)$

Department of Internal Medicine II, University of Tuebingen,

Otfried-Müller-Str. 10,

72076 Tübingen, Germany

e-mail: reinhild.klein@med.uni-tuebingen.de

\author{
Abbreviations \\ ALAT Alanine aminotransferase \\ ANCA Antineutrophil cytoplasmic antibodies \\ AP Alkaline phosphatase \\ ASAT Aspartate aminotransferase \\ CD Cluster of differentiation \\ Cpm Counts per minute \\ CYP Cytochrome P450 \\ DILD Drug-induced liver disease \\ IKS Pharmacovigilance Centre \\ LTT Lymphocyte transformation test \\ MPO Myeloperoxidase \\ PBMC Peripheral blood mononuclear cells \\ SANZ Swiss Drug Monitoring Centre \\ SI Stimulation index \\ ULN Upper limit of normal
}

\section{Introduction}

Liver injury as a side effect of oral anticoagulants - such as the coumarin derivatives phenprocoumon, Warfarin sodium, and acenocoumarol- has been only rarely reported worldwide [1], whereas most frequently, bleeding complications occur. The Swiss Drug Monitoring and the Pharmacovigilance Centers (SANZ and IKS) recounted ten $(1.5 \%)$ oral-anticoagulant-related cases among 674 reports of drug-induced liver disease (DILD) between 1981 and 1995 [2]. In Germany, 0.89\% of all reported drug-induced adverse reactions affecting the liver seem to be phenprocoumon related [1].

Clinically/histologically, phenprocoumon-induced liver disease ranges from mild acute hepatitis to (sub) acute liver failure $[1,3]$. There are only a few reports about cholestatic 
hepatitis $[2,4]$. The mechanisms leading to phenprocoumoninduced liver injury are not entirely clear. There are three case reports suggesting immunological processes due to a positive liver transformation test (LTT) or the activation of CD4-positive memory $\mathrm{T}$ cells [5-7]. Also, eosinophilic infiltrates in liver biopsies of patients with phenprocoumoninduced liver disease would support the concept of an immunologically mediated process, although eosinophilia in the blood or clinical signs of allergy (exanthema, fever) has not been observed $[1,8,9]$.

Over the past 20 years, we collected a series of 30 patients with DILD in whom phenprocoumon was highly suggestive to be the causative agent. We show that 15 of them had sensitized lymphocytes toward this substance, indicating that at least in a subgroup of patients, immunological/allergic processes may, indeed, play a role in the pathogenesis of the liver injury.

\section{Patients and methods}

\section{Patients}

In the period 1997-2007, we received peripheral blood from 204 patients in whom a drug-induced allergic liver disorder had been suspected; 51 of them $(25 \%)$ had taken coumarin derivatives. Twenty-one patients had to be excluded from the study due to the lack of detailed clinical and biochemical data, i.e., 30 patients were further analyzed. In all of them, lymphocyte transformation test (LTT) had been performed in the optimal time period after withdrawal of the drug, which ranged between ${ }^{2} 10$ and 48 days $[11,12]$. Four patients had already taken the drug for more than 5 years. In the remaining 26 patients, the median drug intake until the appearance of DILD was 6 months. There was only one patient in whom features of the injury occurred $24 \mathrm{~h}$ after first intake of the drug. In seven of the 30 patients, the drug had not yet been withdrawn at the time of LTT.

Reasons for phenprocoumon intake were atrial fibrillation $(60 \%)$, mitral valve replacement $(16 \%)$, and coronary heart disease $(8 \%)$. Two further patients received phenprocoumon because of several thromboembolic events; one of them suffered from vasculitis with antibodies to neutrophils/myeloperoxidase (pANCA/MPO). Eighteen patients took other drugs besides phenprocoumon.

The diagnosis of DILD was based on the following International Consensus Meeting criteria [12]: (1) alanine aminotransferase $($ ALAT) $>2$ times the upper limit of normal (ULN); conjugated bilirubin $>2$ times ULN; or combined increase in aspartate aminotransferase (ASAT), alkaline phosphatase (AP), and total bilirubin provided one was $>2$ times ULN; (2) identification of a medicinal agent (in this study, phenprocoumon) with a temporal relationship to elevated liver enzymes; and (3) exclusion of other causes of liver or biliary-tract disease and excessive use of alcohol.

International Consensus Criteria were used to define the pattern of liver injury as hepatocellular, cholestatic, or mixed [13]:

- Hepatocellular: ALAT $\geq 2$ times $\mathrm{ULN}$, or $\mathrm{R} \geq 5(\mathrm{R}=$ ALAT/AP)

- Cholestatic: $\mathrm{AP} \geq 2$ times ULN or $\mathrm{R} \leq 2$

- Mixed: ALAT $\geq 2$ times ULN and AP $\geq 2$ times ULN and $2<\mathrm{R}<5$.

Liver biopsy had been performed in only two of the 30 patients with respect to the possible bleeding complications in the anticoagulated patients; in both, lobular hepatitis with bridging necrosis was described. Clinically/serologically, there was no evidence for autoimmune hepatitis, although it could not be excluded with certainty, as the autoimmune hepatitis score [14] could not be applied due to the lack of histology. However, relevant autoantibodies (antibodies to nuclei, actin, liver-kidney microsomes, soluble liver/ liver-pancreas antigen, mitochondria, neutrophils) could not be detected, and immunoglobulin $\mathrm{G}(\mathrm{IgG})$ was normal. The relationship between liver disease and drug intake was further emphasized in these patients by the fact that liver enzymes and clinical symptoms normalized after withdrawal of the drug. Twenty-four patients received the drug for the first time, and six were accidentally reexposed. In one of them at first exposure, an increase of transaminases was noted. The time from the beginning of drug intake to development or registration of liver injury was significantly shorter in the reexposed patients [mean \pm standard deviation (SD) $91 \pm$ 81 days, median 90 days; range 3-180 days] than in the 24 patients who had received the drug for the first time (mean \pm SD 500 \pm 845 , median:150 days; range 1-3,700 days; $p<$ $0.05)$ Clinical, biochemical, and serological parameters of all 30 patients are shown in Table 1.

Furthermore, peripheral blood was obtained from 10 individuals, who were treated with phenprocoumon for at least 6 months but had no evidence for side effects toward this substance, as well as from 10 healthy individuals who have never received this drug.

\section{Methods}

Lymphocyte transformation test

From each patient, $30-50 \mathrm{ml}$ heparinized blood was drawn for the LTT for diagnostic reasons. Peripheral blood mononuclear cells were isolated within $24 \mathrm{~h}$ by FicollHypaque centrifugation, as described $[15,16]$. Cells were washed two times in Hank's solution and resuspended in 3 million cells/ml in Roswell Park Memorial Institute (RPMI) 
Table 1 Clinical, biochemical and serological parameters in 30 patients in whom phenprocoumon-induced liver disease was suspected ${ }^{\mathrm{a}}$

\begin{tabular}{|c|c|c|c|}
\hline \multicolumn{4}{|l|}{ Parameters } \\
\hline \multirow[t]{2}{*}{ Age (years) } & Mean \pm standard deviation (SD) & $65 \pm 13$ & \\
\hline & Range & $37-84$ & \\
\hline Sex & Females:males & $18: 12$ & \\
\hline $\begin{array}{l}\text { Time of phenprocoumon intake } \\
\text { (months): mean } \pm \text { SD (median) }\end{array}$ & $7 \pm 8(6)^{b}$ & & \\
\hline Biochemical parameters & Normal values & Mean \pm SD (median) & Number (\%) positive \\
\hline ALAT $(\mu \mathrm{kat} / \mathrm{L})$ & $<0.58$ & $6.52 \pm 6.25(4.58)$ & 26 \\
\hline ASAT $(\mu \mathrm{kat} / \mathrm{L})$ & $<0.58$ & $4.78 \pm 4.55(2.62)$ & 27 \\
\hline AP $(\mu \mathrm{kat} / \mathrm{L})$ & $<2.8$ & $5.67 \pm 6.21(3.23)$ & 16 \\
\hline$\gamma \mathrm{GT}(\mu \mathrm{kat} / \mathrm{L})$ & $<0.83$ & $340 \pm 369(204)$ & 26 \\
\hline Bilirubin $(\mu \mathrm{mol} / \mathrm{L})$ & $<26$ & $68.4 \pm 85.5(34.2)$ & 14 \\
\hline $\operatorname{IgG}(\mathrm{g} / \mathrm{L})$ & $<18.00$ & $11.41 \pm 3.93(10.15)$ & 1 \\
\hline $\operatorname{IgA}(\mathrm{g} / \mathrm{L})$ & $<4.00$ & $3.03 \pm 1.79(2.52)$ & 9 \\
\hline $\operatorname{IgM}(\mathrm{g} / \mathrm{L})$ & $<2.80$ & $1.52 \pm 0.97(1.19)$ & 3 \\
\hline \multicolumn{4}{|l|}{ Enzyme profiles (number patients) } \\
\hline Hepatitic & 15 & & \\
\hline Cholestatic & 12 & & \\
\hline Mixed type & 3 & & \\
\hline
\end{tabular}

$A L A T$ alanine aminotransferase, $A S A T$ aspartate aminotransferase, $A P$ alkaline phosphatase, $\gamma G T$ gamma-glutamyl transpeptidase, IgG immunoglobulin $\mathrm{G}, \operatorname{Ig} A$ immunoglobulin A, IgM immunoglobulin $\mathrm{M}$

${ }^{a}$ Autoantibodies indicative for an autoimmune liver disease (antibodies to nuclei, actin, soluble liver/liver-pancreas antigen, liver-kidney microsomes, mitochondria) could not be detected in any of the patients

${ }^{\mathrm{b}}$ Excluding four patients who had taken the drug for more than 5 years

1640 culture medium supplemented with gentamicin and $25 \%$ autologous serum. For the proliferation assay, peripheral blood mononuclear cells $(\mathrm{PBMC})\left(3 \times 10^{5} /\right.$ well $)$ were seeded into 96-well cell culture plates and cultured without antigen, with pokeweed mitogen as a positive control, and with phenprocoumon in five concentrations ranging from 0.1 to $1.000 \mu \mathrm{g} / \mathrm{ml}$ for7 days at $37^{\circ} \mathrm{C}, 5 \% \mathrm{CO}_{2}$ in a humidified atmosphere. Over the final $18 \mathrm{~h}$, the cultures were pulsed with ${ }^{3} \mathrm{H}$-thymidine $(0.74 \mathrm{Mbq} / \mathrm{ml}, 20 \mu \mathrm{l} /$ well $)$ and harvested onto fiberglass filters. The incorporated radioactivity was measured by liquid scintillation spectroscopy using a $\beta$-counter and given as counts per minute (cpm). All cultures were performed four- or five-fold; the mean cpm was used to calculate the stimulation index (SI): $\mathrm{SI}=$ mean $\mathrm{cpm}$ with antigen/mean cpm without antigen.

\section{Laboratory parameters}

Biochemical parameters were analyzed by standard methods. Quantitative immunoglobulins were determined using nephelometry (Beckmann Instruments, Munich, Germany).

\section{Statistical analysis}

For comparison of clinical data in different groups of patients, SPSS version 15.0 was used applying the nonparametric Mann-Whitney test. Differences with $p<$ 0.05 were considered statistically significant.

\section{Results}

Demonstration of sensitized lymphocytes in patients with phenprocoumon-induced liver disease

Fifteen of the 30 patients with suspected phenprocoumoninduced liver disease showed a positive result in the LTT ( $\mathrm{SI}>2.0$; range 2.1-17), that is, they had sensitized lymphocytes against this substance. The reaction was strictly dose dependent, showing positive results in most instances at $10 \mu \mathrm{g}$ phenprocoumon/ml (Fig. 1); thus, in ten patients, the highest SI was observed with $10 \mu \mathrm{g}$, in four patients with $1,000 \mu \mathrm{g}$, and in one patient with $1 \mu \mathrm{g}$ phenprocoumon $/ \mathrm{ml}$. Proliferation of lymphocytes at $10 \mu \mathrm{g} / \mathrm{ml}$ in the 15 LTT-positive patients was, therefore, significantly higher than the spontaneous proliferation or proliferation with phenprocoumon at higher or lower concentrations (Fig. 1).

Six patients had been reexposed to the drug, and four of them $(67 \%)$ were positive in the LTT. Of the 24 patients who had received phenprocoumon for the first time, 11 $(46 \%)$ revealed a positive LTT. Stimulation indices in the 
Fig. 1 Dose-dependent in vitro reactivity of lymphocytes from 15 patients with phenprocoumon-induced liver injury being positive with phenprocoumon in the lymphocyte transformation test $=$ mean values

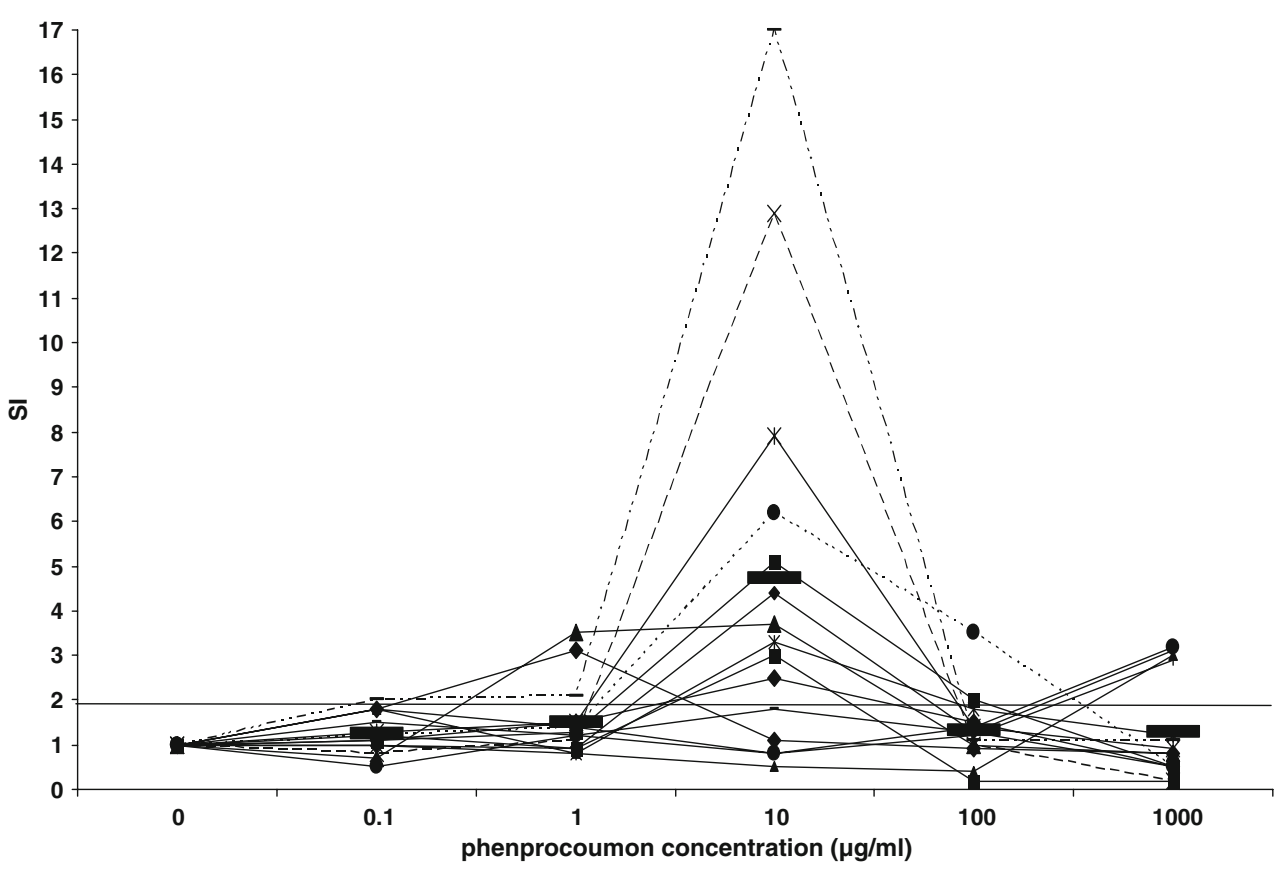

\section{Discussion}

In this study, we could show for the first time in a larger group of 30 patients that in phenprocoumon-induced hepatitis, immunological mechanisms may play an important role. Thus, in 15 of 30 patients $(50 \%)$ with hepatitis or cholestatic liver disease in whom phenprocoumon was highly suspected to be the causative agent due to appropriate time interval and history [13], sensitized lymphocytes against this substance were observed in vitro by LTT, revealing stimulation indices up to 17 . These data confirm previous case reports showing either a positive LTT or activated lymphocytes by flow cytometry [5-7].

The LTT is nowadays accepted as the most consistent in vitro test for identifying a drug suspected of causing allergic disorders, especially hepatitis $[5,6,10,11,17-$ 19]. It is very specific [20] and correlates with the clinical manifestations. Thus, in our study, patients exposed to phenprocoumon but without signs of liver disease or other side effects, as well as healthy blood donors, were negative. This observation and the fact that the in vitro reaction of PBMC from patients with clinically manifest hepatitis was strictly dose dependent emphasizes the specificity of the test and excludes that the observed positive reactions are merely epiphenomena [10]. PBMC of two patients who were positive in the LTT with phenprocoumon could be also tested against two other coumarin derivatives (warfarin and acenocoumarol; data not shown). One patient showed a strong reaction to both substances, whereas the other was negative, indicating that different side chains of the molecules may be involved in the induction of immunological reactions. This may explain why reports about the 
Table 2 Comparison of clinical, biochemical and serological findings in patients with suspected phenprocoumon-induced liver disease being either positive or negative in the lymphocyte transformation test (LTT)

\begin{tabular}{|c|c|c|c|c|}
\hline \multirow[t]{2}{*}{ Parameters } & & \multicolumn{2}{|l|}{ Patients } & \multirow[t]{2}{*}{$P$ value } \\
\hline & & LTT negative $(\mathrm{SI}<2)(n=15)$ & LTT positive $(\mathrm{SI}>2)(n=15)$ & \\
\hline \multirow[t]{2}{*}{ Age (years) } & $\begin{array}{l}\text { Mean } \pm \text { standard deviation } \\
\text { (SD) (median) }\end{array}$ & $71 \pm 11(75)$ & $60 \pm 13(63)$ & \multirow[t]{3}{*}{0.023} \\
\hline & Range & $51-84$ & $37-83$ & \\
\hline Sex & Females:males & $9: 6$ & $9: 6$ & \\
\hline \multicolumn{2}{|c|}{ Time of phenprocoumon intake (months): mean $\pm \mathrm{SD}$ (median) ${ }^{\mathrm{a}}$} & $9 \pm 10(7)$ & $5 \pm 3(6)$ & n.s. \\
\hline \multicolumn{5}{|c|}{ Days from withdrawal of the drug until $\mathrm{LTT}^{\mathrm{a}}$} \\
\hline & Mean $\pm \mathrm{SD}$ (median) & $20 \pm 12(15)$ & $27 \pm 13(24)$ & \multirow[t]{3}{*}{ n.s. } \\
\hline & Range & $9-48$ & $8-46$ & \\
\hline & Not withdrawn & 5 & 2 & \\
\hline \multicolumn{2}{|c|}{ Number patients with reexposure } & 2 & 4 & \\
\hline Biochemical parameters & Normal values & Mean $\pm \mathrm{SD}$ (median) & Mean $\pm \mathrm{SD}$ (median) & \\
\hline ALAT ( $\mu$ kat/L) & $<0.58$ & $5.25 \pm 5.02(4.20)$ & $7.7 \pm 7.2(6.65)$ & n.s. \\
\hline ASAT $(\mu \mathrm{kat} / \mathrm{L})$ & $<0.58$ & $4.43 \pm 4.23(2.05)$ & $5.12 \pm 4.97(3.83)$ & n.s. \\
\hline AP $(\mu k a t / L)$ & $<2.8$ & $4.33 \pm 4.22(3.40)$ & $6.80 \pm 7.48(2.31)$ & n.s. \\
\hline$\gamma \mathrm{GT}(\mu \mathrm{kat} / \mathrm{L})$ & $<0.83$ & $4.33 \pm 4.88(3.30)$ & $6.90 \pm 7.10(4.85)$ & n.s. \\
\hline Bilirubin $(\mu \mathrm{mol} / \mathrm{L})$ & $<26$ & $85.5 \pm 119.7(34.2)$ & $34.2 \pm 34.2(34.2)$ & 0.098 \\
\hline $\operatorname{IgG}(\mathrm{g} / \mathrm{L})$ & $<18.00$ & $11.38 \pm 3.63(10.40)$ & $11.22 \pm 4.10(9.42)$ & n.s. \\
\hline $\operatorname{IgA}(\mathrm{g} / \mathrm{L})$ & $<4.00$ & $3.35 \pm 1.60(2.90)$ & $2.70 \pm 1.93(1.64)$ & n.s. \\
\hline $\operatorname{IgM}(\mathrm{g} / \mathrm{L})$ & $<2.80$ & $1.48 \pm 1.09(1.19)$ & $1.43 \pm 0.86(1.10)$ & n.s. \\
\hline Enzyme profiles & Number (\%) & & & \\
\hline Hepatitic & & $8(53)$ & $7(47)$ & \\
\hline Cholestatic & & $7(47)$ & $5(33)$ & \\
\hline Mixed & & 0 & $3(20)$ & \\
\hline
\end{tabular}

$A L A T$ alanine aminotransferase, $A S A T$ aspartate aminotransferase, $A P$ alkaline phosphatase, $\gamma G T$ gamma-glutamyl transpeptidase, $I g G$ immunoglobulin G, $I g A$ immunoglobulin A, $I g M$ immunoglobulin M, SI stimulation index, n.s. not significant

${ }^{a}$ Excluding the four patients who had been treated with phenprocoumon for more than 5 years

safety of acenocoumarol in patients with phenprocoumoninduced liver diseases are contradictory [21-23].

The sensitivity of the LTT ranges between $15 \%$ and $80 \%$ and depends upon the group of drugs, their metabolites, and antigen presentation [20, 24]. With phenprocoumon, we achieved a sensitivity of $50 \%$, that is, 15 patients with liver injury assumed to be due to phenprocoumon intake were negative in the LTT. There may be several reasons for this. First, false negative LTT results are quite frequent when the test is not performed within the optimal time interval after appearance of symptoms and withdrawal of the drug (14 days to 6 weeks) [10, 11]; however, in our study, we included only those patients in whom this precondition was fulfilled. Second, toxic and nonimmunologic processes may have been responsible for the side effects $[25,26]$. Third, the allergic reaction is no induced by the drug phenprocoumon itself but rather by its metabolites (as, for instance, shown for metamizole-induced adverse reactions [15]), which could not be analyzed in our test system. Fourth, phenprocoumon was not the causative agent. Fifth, the LTT in its present form is not sensitive enough.

Several research groups have tried to improve LTT sensitivity by various modifications such as measuring cytokines in the lymphocyte supernatants, analyzing lymphocyte activation markers such as CD69 by flow cytometry or coculturing lymphocytes with cytokines such as alpha interferon [27-30]. We could not analyze these alternative methods systematically in parallel to the LTT. However, it is our experience with other drugs that LTT results do not correlate with cytokine production or expression of activity markers on lymphocytes (unpublished observations).

The identification of an allergic idiosyncratic drug reaction is currently a circumstantial diagnosis. Characteristics of type 1 allergic disorders such as fever, rash, or eosinophilia have not been described for coumarin-induced hepatopathy, which is rather a type IV (delayed-type hypersensitivity) reaction, and were present in only one of 
our patients. Laboratory parameters are also no reliable indicators for phenprocoumon-induced liver injury, as it may manifest itself either with a hepatitic or cholestatic or even a mixed enzyme profile, as shown in this study. The LTT might therefore be a helpful tool to verify the diagnosis of phenprocoumon-induced liver injury, at least in $50 \%$ of patients, although one must be aware that this test can be performed only in specialized centers.

It remains unclear as to how immunological reactions in phenprocoumon-induced hepatitis are induced. A change in the antigenicity of hepatocytes caused by antigen expression of coumarin metabolites must be considered [3, 8, 9, 31]. Phenprocoumon is highly protein bound and hydroxylated and conjugated in the liver [32-36]. Cytochrome P450 (CYP) 2C9 and CYP3A are the major enzymes involved in the hepatic metabolism of phenprocoumon [32, $33,37]$. Genetic polymorphisms may alter hydroxylation of phenprocoumon, thereby influencing protein binding of its metabolites and formation of neoantigens. Side effects toward this drug may, therefore, depend upon genetic background, but this could not be analyzed in our study. However, environmental factors such as combination with other drugs, including herbal remedies; alcohol; obesity; or infectious processes may also facilitate a phenprocoumonrelated allergic reaction [38-42].

The onset of phenprocoumon-induced liver disease apparently can occur at any time during treatment, according to the literature, between a minimum of 3 and a maximum of 10 [1] months. Latency is reduced to 750 days in the case of reexposure to the respective drugs. These data could be largely confirmed in our patients. However, it became evident that even after treatment of more than 5 years, (allergic) phenprocoumon-induced hepatitis can evolve. We also observed this phenomenon with other drugs, such as nonsteroidal antirheumatics or antiepileptics, used in chronic disorders (unpublished observation). Whether those late manifestations are facilitated by changes in exogenous factors (combination with other drugs; infections) has yet to be evaluated. Interestingly, in one patient who received phenprocoumon for the first time and had never been treated with other coumarin derivatives, DILD occurred as early as $24 \mathrm{~h}$ after intake of phenprocoumon. Considering the fact that coumarins also occur also in plants (e.g., woodruff) or tobacco [43, 44], one could surmise that contact with such environmental antigens led to presensitization and cross-reactivity with phenprocoumon.

In conclusion, we have shown that in a subgroup of patients with phenprocoumon-induced liver injury, allergic mechanisms may play an important role in the pathogenesis of the disease, as shown by a positive LTT. This test may, therefore, help to identify those immunologically mediated side effects. It still has to be evaluated in further studies whether it may also be useful to help exclude in vitro crossreactivity with other coumarin derivatives such as warfarin or acenocoumarol.

Acknowledgements I am indebted to many colleges from different hospitals for sending us blood and clinical and histological data from patients who have been hospitalized because of suspected phenprocoumon-induced liver injury. The data of the 30 patients were obtained from Heinz Kalk-Klinik, Bad Kissingen (Prof. Dr. Chr.-P. Klein, Dr. med. J.-Fr. Kalk; $n=7$ ), Medical Clinic, Ludwigshafen (Prof. Dr. J.F. Riemann; $n=2$ ), Department of Internal Medicine I, Tübingen (Prof. Dr. M. Gregor; $n=1$ ), hospitals in Nagold (Prof. Dr. H. Mörk), Heilbronn (PD Dr. U. Weickert), Bruchsal (Prof. Dr. B. Kohler), Lahr (PD Dr. L. Mohr), Trier Klinikum Mutterhaus der Borromäerinnen (Prof. Dr. T.H. Schürmeyer) (each $n=2$ ), as well as in Bremen (Dr. B. Rühlmann), Bad Krozingen (Prof. Dr. F.-J. Neumann), Hagen (Prof. Dr. T. Scholten), Hof (Prof. Dr. F.W. Busch), Hammelburg (Dr. Nußbaum), Detmold (Prof. Dr. E.-H. Egberts), Gladbeck (Prof. Dr. B. Lembcke), Lüdenscheid (Prof. Dr. R. Hörmann), Regensburg (Prof. Dr. K.-H. Wiedmann), and Wangen (Prof. Dr. H.J. Steinhardt) (each $n=1$ ). Furthermore, I thank Sandra Buck for skilful technical assistance.

\section{References}

1. Schimanski CC, Burg J, Möhler M, Höhler T, Kanzler S, Otto G et al (2004) Phenprocoumon-induced liver disease ranges from mild acute hepatitis to (sub-) acute liver failure. J Hepatol 41:67-74

2. Ciorciaro C, Hartmann K, Stoller R, Kuhn M (1996) Leberschäden durch Coumarin-Antikoagulantien: Erfahrungen der IKS und der SANZ. Schweiz Med Wochenschr 126:2109-2113

3. Mix H, Wagner S, Böker K, Gloger S, Oldhafer KJ, Behrend M et al (1999) Subacute liver failure induced by phenprocoumon treatment. Digestion 60:579-582

4. Woolley S, Burger HR, Zellweger U (1995) Phenprocoumoninduced cholestatic hepatitis. Dtsch Med Wochenschr 120:15071510

5. Dorn-Beineke A, Hassan A-W, Bräutigam J, Hildenbrand R, Dempfle C-E, Schwab M (2003) Phenprocoumon-induced hepatitis as an immunologically mediated drug allergic complication of antithrombotic therapy. Thromb Haemost 90:1210-1213

6. Gondocs C, Szalay L, Balo-Banga JM, Feher J (1990) Syncumar okozta toxikus màjkàrosodàs (in Hungarian). Orv Hetil 131:14771479

7. Schneider AR, Hartmann D, Arnold JC, Bohrer MH, Riemann JF (2001) Phenprocoumon-induced necrotizing hepatitis. Dtsch Med Woschenschr 126:457-459

8. De Man RA, Wilson JH, Schalm SW, ten Kate FJ, van Leer E (1990) Phenprocoumon-induced hepatitis mimicking non-A, nonB hepatitis. J Hepatol 11:318-321

9. Kreiter H, Fink U (1967) Ein Fall von Leberschädigung nach Coumarin Medikation. Med Klin 62:12-15

10. Berg PA, Becker EW (1995) The lymphocyte transformation test a debated method for the evaluation of drug allergic hepatic injury. J Hepatol 22:115-118

11. Pichler WJ, Tilch J (2004) The lymphocyte transformation test in the diagnosis of drug hypersensitivity. Allergy 59:809-820

12. Benichou C (1990) Criteria of drug-induced liver disorders. Report of an international consensus meeting. J Hepatol 11:272-276

13. Danan G, Benichou C (1999) Causality assessment of adverse reactions to drugs - I. A novel method based on the conclusions of international consensus meetings: application to drug-induced liver injuries. J Clin Epidemiol 46:1323-1330 
14. Hennes EM, Zeniya M, Czaja AJ, Parés A, Dalekos GN, Krawitt EL et al (2008) Simplified criteria for the diagnosis of autoimmune hepatitis. Hepatology 48:169-176

15. Brattig NW, Diao GJ, Berg PA (1988) The specificity of the lymphocyte transformation test in a patient with hypersensitivity reactions to pyrazolone compounds. A 10-week follow-up study before and after rechallenge. Eur J Clin Pharmacol 35:39-45

16. Klein R, Buck S, Claßen K, Rostock M, Huber R (2008) Enhanced in vitro activation of immunocompetent cells in healthy individuals being subcutaneously 'vaccinated' with placebo (physiological saline). Clin Immunol 126:322-331

17. Bircher AJ, Harr T, Hohenstein L, Tsakiris DA (2006) Hypersensitivity reactions to anticoagulant drugs: diagnosis and management options. Allergy 61:1432-1440

18. Castell JV, Castell M (2006) Allergic hepatitis induced by drugs. Curr Opin Allergy Clin Immunol 6:258-265

19. Romano A, Demoly P (2007) Recent advances in the diagnosis of drug allergy. Curr Opin Allergy Clin Immunol 7:299-303

20. Nyfeler B, Pichler WJ (1997) The lymphocyte transformation test for the diagnosis of drug allergy: sensitivity and specificity. Clin Exp Allergy 27:175-181

21. Neef M, Kerekes Z, Fischer HP, Sauerbruch T, Spengler U (2002) Acenocoumarol is not a safe alternative for anticoagulation in phenprocoumon-induced hepatic failure. Digestion 67:100-104

22. Capoferri M, Realini S, Balestra B (2000) Acute necrotizing hepatitis: an unusual side effect of oral anticoagulants. Schweiz Rundsch Med Prax 89:929-932

23. Ehrenforth S, Schenk JF, Scharrer I (1999) Liver damage induced by coumarin anticoagulants. Semin Thromb Hemost 25:79-83

24. Berg PA, Becker EW, Stein GM (1999) Praxisbedeutsame Methoden zum Nachweis allergisch bedingter UAWs. In: MüllerOerlinghausen B, Lasek R, Düppenbecker H, Munter K-H (eds) Handbuch der unerwünschten Arzneimittelnebenwirkungen. Urban \& Fischer, München, Jena, pp 637-649

25. Suttie JW (1985) Vitamin K-dependent carboxylase. Annu Rev Biochem 54:459-477

26. Vermeer C (1984) The vitamin K-dependent carboxylation reaction. Mol Cell Biochem 61:17-35

27. Merck HF (2005) Diagnosis of drug hypersensitivity: lymphocyte transformation test and cytokines. Toxicology 209:217-220

28. Moed H, von Blomberg M, Bruynzeel DP et al (2005) Improved detection of allergen-specific T-cell responses in allergic contact dermatitis through the addition of 'cytokine cocktails'. Exp Dermatol 14:634-640

29. von Baehr V, Mayer W, Liebenthal C et al (2001) Improving the in vitro antigen specific $\mathrm{T}$ cell proliferation assay: the use of interferon-alpha to elicit antigen specific stimulation and decrease bystander proliferation. J Immunol Methods 251:63-71
30. Kanny G, Pichler W, Morisset M et al (2005) T cell-mediated reactions to iodinated contrast media: evaluation by skin and lymphocyte activation test. J Allergy Clin Immunol 115:179185

31. Holt MP, Ju C (2006) Mechanisms of drug-induced liver injury. AAPS J 8:E48-E54

32. Kammerer B, Kahlich R, Ufer M, Schenkel A, Laufer S, Gleiter $\mathrm{CH}$ (2005) Stereospecific pharmacokinetic characterisation of phenprocoumon metabolites, and mass-spectrometric identification of two novel metabolites in human plasma and liver microsomes. Anal Bioanal Chem 383:909-917

33. Kirchheiner J, Ufer M, Walter E-C, Kammerer B, Kahlich R, Meisel C et al (2004) Effects of CYP2C9 polymorphisms on the pharmacokinetics of $R$ - and $S$-phenprocoumon in healthy volunteers. Pharmaogenetics 14:19-26

34. De Vries JX, Völker U (1990) Determination of the plasma protein binding of the coumarin anticoagulants phenprocoumon and its metabolites, warfarin and acenocoumarol, by ultrafiltration and high-performance liquid chromatography. J Chromatogr 529:479-485

35. He M, Korzekwa KR, Jones JP, Rettie AE, Trager WF (1999) Structural forms of phenprocoumon and warfarin that are metabolized at the active site of CYP2C9. Arch Biochem Biophys 372:16-28

36. Toon S, Heimark LD, Trager WF, O'Reilly RA (1985) Metabolic fate of phenprocoumon in humans. J Pharm Sci 74:1037-1040

37. Ufer M, Svensson JO, Krausz KW, Gelboin HV, Rane A, Tybring G (2004) Identification of cytochromes P450 2C9 and 3A4 as the major catalysts of phenprocoumon hydroxylation in vitro. Eur $\mathrm{J}$ Clin Pharmacol 60:173-182

38. Enderle C, Müller W, Grass U (2001) Drug interaction: omeprazole and phenprocoumon. BMC Gastroenterol 1:2-4

39. Penning-van Beest FJ, Koerselman J, Herings RM (2008) Risk of major bleeding during concomitant use of antibiotic drugs and coumarin anticoagulants. J Thromb Haemost 6:284-290

40. Hu Z, Yang X, Ho PCL, Chan SY, Heng PWS, Chan E et al (2005) Herb-drug interactions. Drugs 65:1239-1282

41. Kaplowitz N (2005) Idiosyncratic drug hepatotoxicity. Nat Rev Drug Discov 4:489-499

42. zu Schwabedissen CM, Mevissen V, Schmitz F, Woodruff S, Langebartels G, Rau T et al (2006) Obesity is associated with a slower response to initial phenprocoumon therapy whereas CYP2C9 genotypes are not. Eur J Clin Pharmacol 62:713-720

43. Brooker NL, Kuzimichev Y, Laas J, Pavlis R (2007) Evaluation of coumarin derivatives as anti-fungal agents against soil-borne fungal pathogens. Commun Agric Appl Biol Sci 72:785-793

44. Givel M (2003) A comparison of US and Norwegian regulation of coumarin in tobacco products. Tob Control 12:401-405 